\title{
Expression and function of Toll-like receptors in peripheral blood mononuclear cells in patients with ankylosing spondylitis
}

\author{
JUN ZHANG，RONGMING XU, LEI WU and JIHONG JIANG \\ Department of Orthopedics, Mingzhou Hospital of Zhejiang University, Ningbo, Zhejiang 315000, P.R. China
}

Received July 10, 2018; Accepted May 29, 2019

DOI: $10.3892 / \mathrm{mmr} .2019 .10631$

\begin{abstract}
Ankylosing spondylitis (AS) is a common chronic inflammatory autoimmune disease. Toll-like receptors (TLRs) are involved in non-specific immunity. In the present study, the roles of TLRs in AS were investigated. The levels of inflammatory cytokines were detected by ELISA and reverse transcription-quantitative polymerase chain reaction (RT-qPCR). The expression levels of TLRs and nuclear factor- $\kappa \mathrm{B}(\mathrm{NF}-\kappa \mathrm{B})$ signaling-associated factors were determined via RT-qPCR and western blot analyses. It was observed that the levels of interleukin (IL)-6, tumor necrosis factor- $\alpha$ (TNF- $\alpha)$, C-reactive protein, TLR4 and TLR5 were increased in patients with AS, whereas those of IL-10 and TLR3 were decreased. Pomalidomide, a TNF- $\alpha$ release inhibitor, reduced the expression of IL- 6 , TNF- $\alpha$, TLR4, TLR5 and phosphorylated-p65, and upregulated that of IL-10, TLR3 and p65 in peripheral blood mononuclear cells from patients with AS. Treatment of patients with infliximab, an anti-TNF- $\alpha$ monoclonal antibody, induced similar effects in vivo. In conclusion, it was revealed that inhibition of TNF- $\alpha$ suppressed inflammatory responses in patients with AS, increased the expression of TLR3 and decreased NF- $\mathrm{NB}$ signaling, and the expression of TLR4 and TLR5. The results indicated that TLRs and the NF- $\kappa \mathrm{B}$ signaling pathway were involved in the regulation of inflammatory responses in AS. These findings provided insight into the mechanisms underlying the development of AS and potential novel therapeutic approaches.
\end{abstract}

\section{Introduction}

Ankylosing spondylitis (AS) is a common chronic inflammatory autoimmune disease, which is characterized by inflammation of the spine, and frequently involves inflammation of tendons,

Correspondence to: Dr Rongming Xu, Department of Orthopedics, Mingzhou Hospital of Zhejiang University, 168 West Taian Road, Ningbo, Zhejiang 315000, P.R. China

E-mail: rongmx_xurm@163.com

Key words: ankylosing spondylitis, Toll-like receptors, inflammatory cytokines, nuclear factor $\kappa$-light-chain-enhancer of activated B cells peripheral joints, the attachment points of tendon ligaments and other cartilaginous tissue, leading to spinal rigidity and fibrosis (1). The incidence of AS varies across regions, ages and genders. It was previously reported that the incidence of AS was $0.25 \%$ in Europe (2) and $0.23 \%$ in China (3). The disease frequently occurs in young adults (4). AS progresses slowly, with the development of long-term disability in 20-30\% of cases (5). At present, there is no cure available for AS, with treatment limited to the relief of symptoms $(6,7)$. Therefore, further investigation into the pathogenesis is required.

Toll-like receptors (TLRs) are a class of receptors involved in non-specific immunity, acting as a bridge to link the non-specific and specific immune responses (8). TLRs are single transmembrane domain-containing non-catalytic proteins that identify and bind conserved molecules from microorganisms (9). When microorganisms infiltrate physical barriers such as skin and mucous membranes, TLRs bind them and stimulate immune cell responses $(10,11)$. TLRs are involved in various immune system diseases, including AS, rheumatoid arthritis, osteoarthritis and autoimmune myositis (12-14).

As a regulator of signal transduction, the nuclear factor- $\kappa \mathrm{B}$ $(\mathrm{NF}-\kappa \mathrm{B})$ protein complex is involved in various biological processes, including inflammation, immune response and apoptosis, and has received increasing attention in recent years $(15,16)$. The $\mathrm{NF}-\kappa \mathrm{B}$ signaling pathway in mammals primarily involves the p65/p50 heteromer, which binds its inhibitory protein [inhibitor of NF- $\kappa \mathrm{B} B(\mathrm{I} \kappa \mathrm{B})$ subunit $\mathrm{I} \kappa \mathrm{B} \alpha$ ], masking the nuclear translocation signal of $N F-\kappa B(17)$. $\mathrm{NF}-\kappa \mathrm{B}$ exists in an inactive form in the cytoplasm; however, following phosphorylation of $\mathrm{I} \kappa \mathrm{B}$ by I $\mathrm{I} \mathrm{B}$ kinase, I $\mathrm{I} \mathrm{B} \alpha$ separates from $N F-\kappa B$ and activated $N F-\kappa B$ is translocated into the nucleus (17). It has been reported that NF- $\kappa \mathrm{B}$ signaling serves important roles in the progression of AS, rheumatoid arthritis and various cancers (18-20).

In the present study, the expression levels of inflammatory cytokines and TLRs were determined in healthy subjects and patients with AS. The inflammatory cytokines, TLRs and $\mathrm{NF}-\kappa \mathrm{B}$ signaling were analyzed in peripheral blood mononuclear cells (PBMCs) from patients with AS prior to and following treatment.

\section{Materials and methods}

Patients. A total of 30 patients (male patients, 21; female patients, 9) with AS were recruited at Mingzhou Hospital of 
Zhejiang University (Ningbo, China) between May 2015 and April 2017, aged between 26 and 69 years old with an average age of $37.25 \pm 10.17$ years. Patients were diagnosed with AS according to the New York diagnostic standard of AS revised in 1984 (21). Patients were excluded from the study based on the following criteria: Serious lesion of the heart, brain, liver, kidney or other important organs; diagnosis of blood or endocrine system diseases; the primary lesion was not located in the spine; diagnosis of psoriasis, inflammatory bowel disease or uveitis; pregnancy; lactation or diagnosis of acute ophthalmia requiring corticosteroid therapy. A total of 30 healthy subjects (male patients, 20; female patients, 10) aged between 27 and 66 years old (average age, 36.94 \pm 10.65 years) were included as controls; these subjects were recruited during physical examinations between May 2015 and April 2017. Healthy controls were excluded according to the following criteria: The aforementioned exclusion criteria; and diseases or symptoms of the spinal joints, chronic diseases or autoimmune diseases. All patients provided written informed consent prior to the collection of blood samples, and all experiments were approved by the Ethics Committee of Mingzhou Hospital of Zhejiang University. Patients received three doses of infliximab $(5 \mathrm{mg} / \mathrm{kg})$, with subsequent doses received 2 and 6 weeks following the first dose.

Source and culture of cells. PBMCs were obtained from patients with AS by Ficoll-Hypaque (Ficoll ${ }^{\mathrm{TM}}$ Paque Plus; cat. no. 17-1440-03; GE Healthcare) density gradient centrifugation as previously described (22). PBMCs were maintained in RPMI-1640 medium (Shanghai BioSun SciTech Co., Ltd.) containing $10 \%$ fetal bovine serum (HyClone; GE Healthcare Life Sciences) and 1\% penicillin-streptomycin (Beijing Leagene Biotech Co., Ltd.) in an incubator (Shanghai SANTN Instrument Co., Ltd.) at $37^{\circ} \mathrm{C}$ with $95 \%$ humidified air and $5 \%$ $\mathrm{CO}_{2}$. Following $24 \mathrm{~h}$ of culture, the morphology of the cells was observed under an inverted microscope (x100 and x200; XDS-100; Shanghai Caikon Optical Instrument Co., Ltd.).

Reagents and experimental grouping. Tumor necrosis factor- $\alpha$ (TNF- $\alpha)$ was purchased from MedChemExpress. Pomalidomide (anti-TNF- $\alpha$; Selleck Chemicals) is a derivative of thalidomide and inhibits TNF- $\alpha$ release induced by lipopolysaccharide (23). It has been reported that as an analogue of thalidomide, pomalidomide exhibits antiapoptotic, antiangiogenic and immunomodulatory activities $(24,25)$.

PBMCs were collected from three groups: Healthy individuals (control); patients with AS prior to treatment (AS/Before treatment) and patients following treatment with infliximab (After treatment). PBMCs were then assigned to five groups: PBMCs not treated with TNF- $\alpha$ or anti-TNF- $\alpha$ (control); PBMCs cultured with 1,5 and $10 \mathrm{ng} / \mathrm{ml}$ TNF- $\alpha$; and PBMCs cultured with $2 \mu \mathrm{M}$ pomalidomide $(2 \mu \mathrm{M}$ anti-TNF- $\alpha)$.

ELISA. Serum samples were isolated from blood samples via centrifugation at $2,000 \mathrm{x} \mathrm{g}$ for $10 \mathrm{~min}$ at room temperature. The levels of interleukin (IL)-6, IL-10, TNF- $\alpha$ and C-reactive protein (CRP) in serum were detected using ELISA kits (Shanghai Enzyme-linked Biotechnology Co., Ltd.) according to the manufacturer's protocols. In brief, the samples were added to wells coated with polyclonal antibodies against IL-6 (cat. no. ml058097-1), IL-10 (cat. no. m1064299-1), TNF- $\alpha$ (cat. no. ml077385-1) and CRP (ml002999-1), and proteins were detected using biotinylated monoclonal anti-human antibodies at room temperature for $2 \mathrm{~h}$. After washing with PBS, color development was catalyzed by horseradish peroxidase conjugated to streptavidin and terminated using $2 \mathrm{M}$ sulfuric acid. The absorbance was detected at $450 \mathrm{~nm}$, and the protein content was determined by normalizing the relative absorbance of the samples to the standards.

Reverse transcription-quantitative PCR (RT-qPCR). Total RNA was isolated from tissues and cells and extracted using TRIzol $^{\circledR}$ reagent (Thermo Fisher Scientific, Inc.). RNA ( $\left.1 \mu \mathrm{g}\right)$ was reverse transcribed to obtain cDNA using a RevertAid ${ }^{\mathrm{TM}}$ cDNA Synthesis kit (Thermo Fisher Scientific, Inc.), with the reaction conditions set at $85^{\circ} \mathrm{C}$ for $5 \mathrm{~min}$. qPCR was performed using an ABI 7500 system (Applied Biosystems; Thermo Fisher Scientific, Inc.) and iTaq ${ }^{\mathrm{TM}}$ Universal SYBR $^{\circledR}$ Green (Bio-Rad Laboratories, Inc.). qPCR was conducted as follows: Initial denaturation at $92^{\circ} \mathrm{C}$ for $5 \mathrm{~min} ; 30$ cycles of denaturation (at $92^{\circ} \mathrm{C}$ for $30 \mathrm{sec}$ ) and annealing (at $62^{\circ} \mathrm{C}$ for $30 \mathrm{sec}$ ); and extension at $72^{\circ} \mathrm{C}$ for $30 \mathrm{sec}$. The primers were acquired from Invitrogen (Thermo Fisher Scientific, Inc.) and are presented in Table I. The internal reference was $\beta$-actin, and gene expression was quantified using the $2^{-\Delta \Delta \mathrm{Cq}}$ method (26). This experiment was repeated at least three times.

Western blotting. Protein was isolated from cells and extracted using radioimmunoprecipitation assay lysis buffer (Beijing Leagene Biotech Co., Ltd.), and the total protein was quantified using a bicinchoninic acid detection assay kit (Shanghai Yeasen Biotechnology, Co., Ltd.). Proteins ( $20 \mu \mathrm{g} / \mathrm{lane})$ were separated via $10 \%$ SDS-PAGE and transferred to nitrocellulose membranes. The membranes were blocked in $5 \%$ dried skimmed milk in TBS buffer at $37^{\circ} \mathrm{C}$ for $1 \mathrm{~h}$ and incubated overnight at $4^{\circ} \mathrm{C}$ with antibodies against TLR3 (1:700; ab62566, Abcam), TLR4 (1:600; ab13556, Abcam), TLR5 (1:800; ab62460, Abcam), p65 (1:1,000; ab32536, Abcam), phosphorylated (p)-p65 (1:600; ab86299, Abcam) and $\beta$-actin (1:1,000; MAB8969, R\&D Systems, Inc.). Then, the membranes were washed in TBS-0.1\% Tween-20 three times, and incubated at room temperature for $1.5 \mathrm{~h}$ with the following secondary antibodies: Mouse anti-rabbit IgG, (1:6,000; cat. no. 3678; Cell Signaling Technology, Inc.); horseradish peroxidase (HRP)-conjugated rabbit anti-mouse IgG (1:7,000; cat. no. 58802; Cell Signaling Technology, Inc.) and HRP-conjugated rabbit anti-goat IgG (1:6,000; sc-2768; Santa Cruz Biotechnology, Inc.). Bands were visualized using enhanced chemiluminescence detection reagent (Amersham; GE Healthcare) and imaged using an iBright ${ }^{\mathrm{TM}}$ CL1000 imaging system (iBright analysis software, version 1.2.0; Thermo Fisher Scientific, Inc.).

Statistical analysis. Data were analyzed using IBM SPSS Statistics version 20 (IBM Corp.). Data were presented as the mean \pm standard deviation. All experiments were performed in triplicate. Differences between groups were determined using one-way analyses of variance followed by a Tukey's post hoc test. $\mathrm{P}<0.05$ was considered to indicate a significant difference. 
Table I. Sequences of primers.

\begin{tabular}{|c|c|}
\hline Primer name & Sequence $\left(5^{\prime}-3^{\prime}\right)$ \\
\hline TLR1-Forward & GGAGGCAATGCTGCTGTT \\
\hline TLR1-Reverse & GCCCAATATGCCTTTGTTATCCTG \\
\hline TLR2-Forward & TGTTGCAAGCAGGATCCAAAG \\
\hline TLR2-Reverse & CACAAAGTATGTGGCATTGTCCAG \\
\hline TLR3-Forward & GGACTTTGAGGCGGGTGTT \\
\hline TLR3-Reverse & TGTTGAACTGCATGATGTACCTTG \\
\hline TLR4-Forward & AGGATGATGCCAGCATGATGTC \\
\hline TLR4-Reverse & TCAGGTCCAGGTTCTTGGTTGAG \\
\hline TLR5-Forward & AAGATGTCGGAGCCTCAGATG \\
\hline TLR5-Reverse & GGGTCCCTGGTTGTTTAAAGACTTC \\
\hline TLR6-Forward & CAGAGTGAGTGGTGCCATTACGA \\
\hline TLR6-Reverse & AGCCTTCAGCTTGTGGTACTTGTTC \\
\hline TLR7-Forward & TCTTCAACCAGACCTCTACATTCCA \\
\hline TLR7-Reverse & GGAACATCCAGAGTGACATCACAG \\
\hline TLR8-Forward & GCGCTGCTGCAAGTTACGGA \\
\hline TLR8-Reverse & TCGACGATTGCTGCACTCTG \\
\hline TLR9-Forward & GGGACCTCGAGTGTGAAGCA \\
\hline TLR9-Reverse & CTGGAGCTCACAGGGTAGGAA \\
\hline IL-6-Forward & AACCTGAACCTTCCAAAGATGG \\
\hline IL-6-Reverse & TCTGGCTTGTTCCTCACTACT \\
\hline IL-10-Forward & CCTGCCTAACATGCTTCGAG \\
\hline IL-10-Reverse & GAGTTCACATGCGCCTTGAT \\
\hline TNF- $\alpha$-Forward & ATGAGCACTGAAAGCATGATCC \\
\hline TNF- $\alpha$-Reverse & GAGGGCTGATTAGAGAGAGGTC \\
\hline$\beta$-actin-Forward & GTGGACATCCGCAAAGAC \\
\hline$\beta$-actin-Reverse & AAAGGGTGTAACGCAACTAA \\
\hline
\end{tabular}

IL, interleukin; TLR, toll-like receptor; TNF- $\alpha$, tumor necrosis factor- $\alpha$.

\section{Results}

Upregulation of IL-6, TNF- $\alpha, C$-reactive protein (CRP), TLR4 and TLR5, and downregulation of IL-10 and TLR3 in patients with AS. To investigate the levels of inflammatory cytokines and TLRs in patients with AS, ELISA and RT-qPCR analysis were performed. It was revealed that the serum levels of IL-6, TNF- $\alpha$ and CRP were significantly increased in patients with AS compared with in healthy individuals, whereas those of IL-10 were decreased ( $\mathrm{P}<0.05$; Fig. 1A-D). Additionally, it was demonstrated that the expression of TLR4 and TLR5 mRNA was significantly upregulated in patients with AS compared with the control, whereas that of TLR3 was downregulated $(\mathrm{P}<0.05$; Fig. 1E). The mRNA expression levels of the other TLRs were not significantly different between the two groups.

$T N F-\alpha$ regulates the expression of inflammatory cytokines in PBMCs. PBMCs from patients with AS were identified under an inverted microscope. The cells were round and clustered together (Fig. 2A). The levels of inflammatory cytokines were determined via RT-qPCR analysis to investigate the effects of TNF- $\alpha$ and anti-TNF- $\alpha$ on PBMCs. It was revealed that TNF- $\alpha$ significantly promoted the expression of IL-6 mRNA level in a dose-dependent manner compared with the control; however, IL-10 expression was markedly unaltered following TNF- $\alpha$ treatment $(\mathrm{P}<0.05$; Fig. $2 \mathrm{~B}$ and $\mathrm{C})$. Conversely, anti-TNF- $\alpha$ significantly downregulated the expression of IL-6 compared with the control, and upregulated that of IL-10. Furthermore, TNF- $\alpha(5 \mathrm{ng} / \mathrm{ml})$ significantly increased the expression of TNF- $\alpha$ mRNA in PBMCs; however, expression was significantly downregulated following treatment with anti-TNF- $\alpha$ $(\mathrm{P}<0.05$; Fig. 2D).

$T N F-\alpha$ regulates the expression of TLRs and $N F-\kappa B$ signaling in PBMCs. To investigate the effects of TNF- $\alpha$ and anti-TNF- $\alpha$ on PBMCs, the expression of TLRs and the activation of $\mathrm{NF}-\kappa \mathrm{B}$ signaling were determined via Western blotting. It was revealed that treatment with TNF- $\alpha$ significantly upregulated the expression of TLR4 and TLR5 protein, and the phosphorylation of p65 compared with the control, whereas it downregulated the expression of TLR3 and p65 $(\mathrm{P}<0.05$, Fig. 3A-E). Conversely, anti-TNF- $\alpha$ treatment significantly downregulated the expression of TLR4 and TLR5, and the phosphorylation of p65; the expression levels of TLR3 and p65 protein were markedly unaltered following anti-TNF- $\alpha$ treatment.

Upregulated expression of IL-10 and TLR3, and downregulated expression of IL-6, TNF- $\alpha, C R P, T L R 4$ and TLR5 following the treatment of patients with AS. An ELISA was conducted to investigate alterations in the serum expression levels of inflammatory cytokines and TLRs following the treatment of patients with AS. It was revealed that the levels of IL-6, TNF- $\alpha$ and CRP were significantly reduced following treatment with infliximab compared with prior to treatment, whereas those of IL-10 were increased ( $\mathrm{P}<0.05$; Fig. 4A-D). Additionally, RT-qPCR analysis demonstrated that treatment with infliximab significantly upregulated the expression of TLR3 mRNA compared with levels prior to treatment, whereas the expression levels of TLR4 and TLR5 mRNA were downregulated $(\mathrm{P}<0.05$; Fig. 4E). The mRNA expression levels of the other TLRs were not significantly altered following treatment.

Upregulated expression of TLR3, and downregulated expression of TLR4, TLR5, p65 and p-p65 following treatment of patients with $A S$. To further investigate the protein expression of TLRs and NF- $\mathrm{KB}$ p 65 signaling prior to and following treatment of patients with AS, western blotting was performed. It was revealed that TLR3 protein expression was significantly upregulated $(\mathrm{P}<0.05$; Fig. $5 \mathrm{~A}$ and $\mathrm{B})$, whereas the protein levels of TLR4 and TLR5, and phosphorylation of p65 were significantly downregulated following treatment $(\mathrm{P}<0.01$; Fig. 5A and C-E), compared with prior to treatment.

\section{Discussion}

AS is a rheumatic disease characterized by inflammation (1), of which cytokines are important mediators. It has been hypothesized that alterations in cell networks are important features of the pathology of AS (27). Cytokines can be divided into proand anti-inflammatory cytokines, depending on their function during inflammatory responses. Proinflammatory cytokines 
A

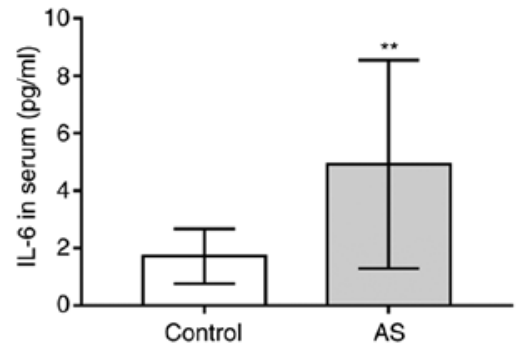

C

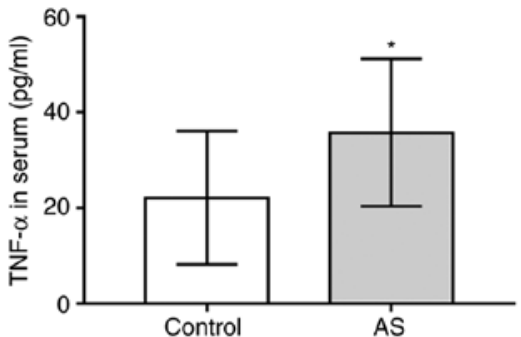

B

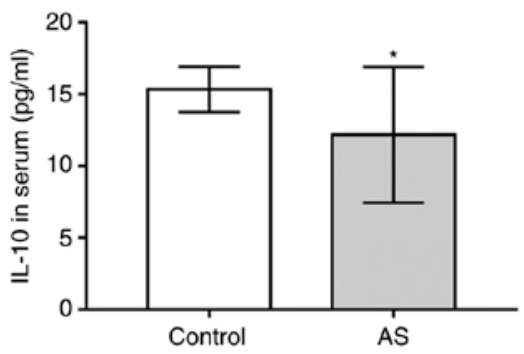

$\mathrm{D}$

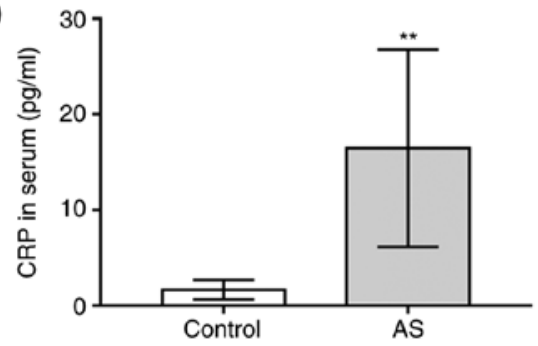

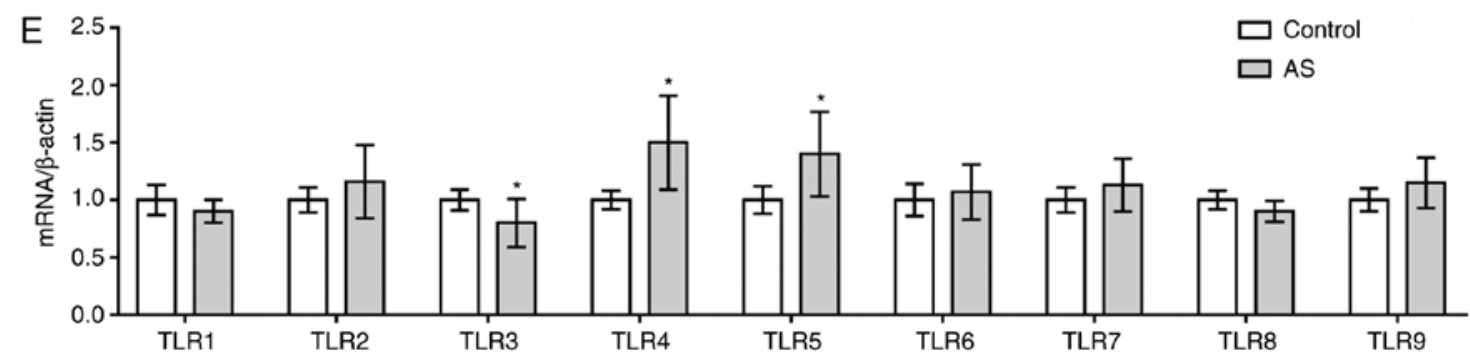

Figure 1. Upregulation of IL-6, TNF- $\alpha$, CRP, TLR4 and TLR5, and downregulation of IL-10 and TLR3 in patients with AS. Serum contents of (A) IL-6, (B) IL-10, (C) TNF- $\alpha$ and (D) CRP in patients with AS and healthy subjects as determined by ELISA. (E) mRNA levels of TLRs as determined via reverse transcription-quantitative PCR analysis. ${ }^{*} \mathrm{P}<0.05,{ }^{* * *} \mathrm{P}<0.01$ vs. control. AS, ankylosing spondylitis; CRP, C-reactive protein; IL, interleukin; TLR, Toll-like receptor; TNF- $\alpha$, tumor necrosis factor- $\alpha$.

A

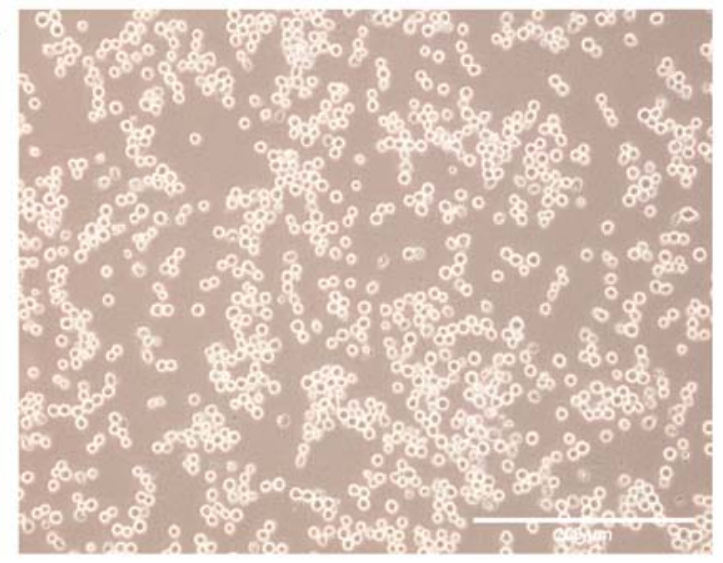

B

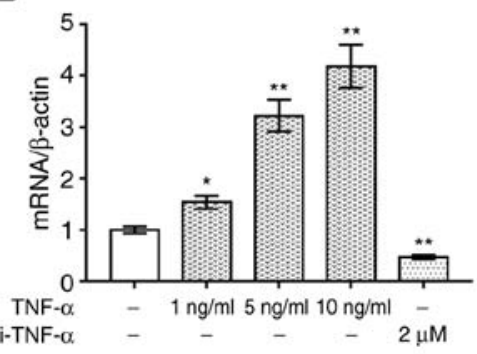

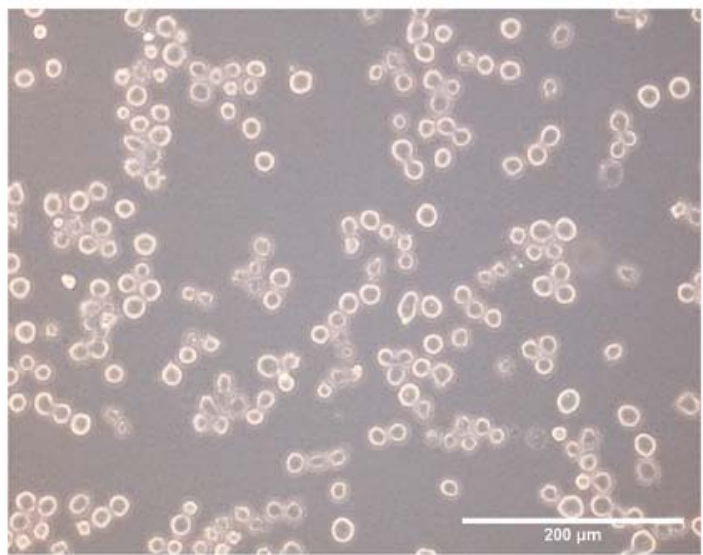

IL-10

D TNF- $\alpha$
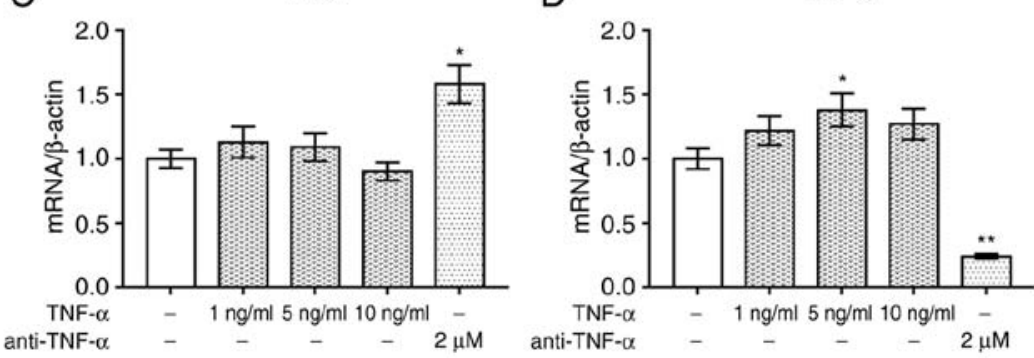

Figure 2. TNF- $\alpha$ regulates the expression of inflammatory cytokines in PBMCs. (A) Morphology of PBMCs isolated from patients was observed under an inverted microscope (left image: Magnification, x100; right image: Magnification, $\mathrm{x} 200$ ). PBMCs were exposed to TNF- $\alpha$ (1, 5 and 10 ng/ml) and $2 \mu \mathrm{M}$ pomalidomide (anti-TNF- $\alpha$ ); the mRNA levels of (B) IL-6, (C) IL-10 and (D) TNF- $\alpha$ were determined via reverse transcription-quantitative PCR analysis. ${ }^{*} \mathrm{P}<0.05,{ }^{* *} \mathrm{P}<0.01$ vs. control. IL, interleukin; PBMC, peripheral blood mononuclear cell; TNF- $\alpha$, tumor necrosis factor- $\alpha$. 


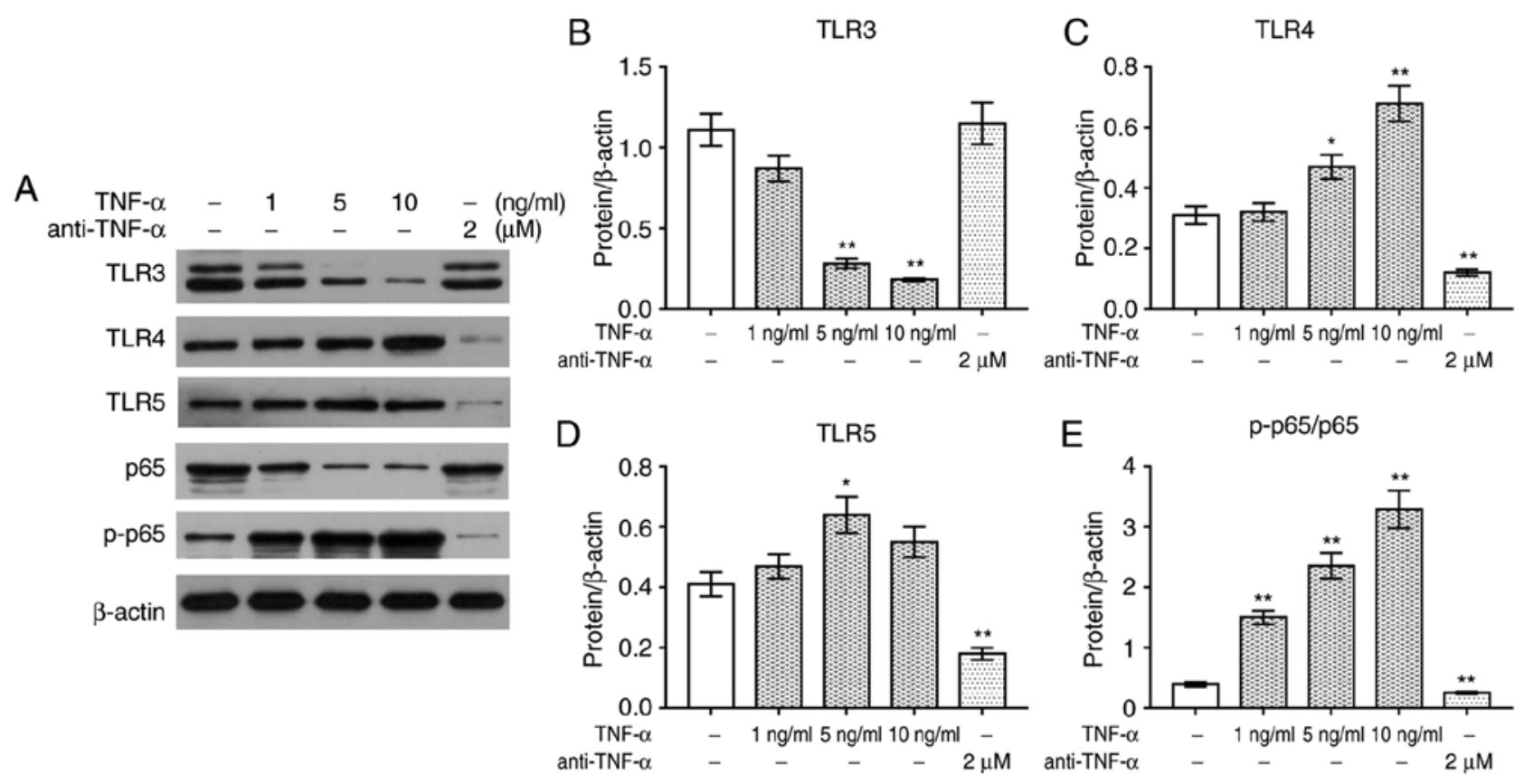

Figure 3. TNF- $\alpha$ mediates TLR expression and NF- $\mathrm{\kappa B}$ p65 signaling in PBMCs. (A) Western blotting was performed to detect the protein levels of TLR3, TLR4, TLR5, p65 and p-p65. Protein expression of (B) TLR3, (C) TLR4, (D) TLR5 and (E) p-p65/p65 presented as bar diagrams. $\beta$-actin was used as an internal control. "P<0.05, ${ }^{* *} \mathrm{P}<0.01$ vs. control. NF- $\mathrm{KB}$, nuclear factor- $\mathrm{KB}$; $\mathrm{p}-$, phosphorylated; PBMC, peripheral blood mononuclear cell; TLR, Toll-like receptor; TNF- $\alpha$, tumor necrosis factor- $\alpha$.

include TNF- $\alpha$, IL-1, IL-6, IL-8, interferon (IFN)- $\gamma$, macrophage migration inhibitory factors, IL-17A and IL-23 $(28,29)$, whereas anti-inflammatory cytokines include IL-2, IL-10, IL-13, transforming growth factor- $\beta$ (TGF- $\beta$ ) and IL-35 (30-32). CRP is the first detected inflammatory acute phase reaction protein, and its levels are closely associated with the degree of inflammation in the disease. CRP is notably upregulated during inflammation $(33,34)$. In the present study, increased levels of IL-6, TNF- $\alpha$ and CRP, and decreased levels of IL-10 were observed in patients with AS, compared with in healthy subjects. TNF- $\alpha$ is an important proinflammatory factor mainly produced by mononuclear macrophages, and is involved in a series of immune responses (35). A previous study suggested that TNF- $\alpha$ was important for the inflammatory response to AS (36). In the present study, it was revealed that TNF- $\alpha$ inhibitor attenuated the inflammatory response of PBMCs in patients with AS by suppressing IL-6 expression and promoting IL-10 expression. Data concerning the effects of TNF- $\alpha$ inhibition on the expression of CRP will enable the development of more firm conclusions. Furthermore, analysis of the levels of additional inflammatory factors, including IL-1, IL-13 and TGF- $\beta$, will be considered to further investigate the inflammatory response to AS.

TLRs serve an important role in the interaction between the immune system and pathogens, which are similar to the effects of nucleotide-binding oligomerization domain-containing protein 2 on diabetic nephropathy disease (37). Following activation, TLRs induce specific gene expression via cell signal transduction, promoting the secretion of cytokines and chemokines (38-40). TLR4, a ligand of LPS, hyaluronic acid and heat shock protein, can promote the production of TNF- $\alpha$, IFN, IL-12 and more proinflammatory factors, inducing inflammatory damage (41). Kragstrup et al (42) reported that
TLR2 and TLR4-induced IL-19 dampened immune reactions, and was inversely associated with spondyloarthritides (SpA) disease activity. Assassi et al (43) reported that TLR4 and TLR5 levels were upregulated in the plasma of patients with AS. Similarly, elevated expression levels of TLR4 and TLR5 were observed in patients with AS in the present study, compared with in healthy subjects. De Rycke et al (44) reported that TLR2 and TLR4 expression was enhanced in patients with SpA. Conversely, in the present study, TLR2 expression was not significantly different in patients with AS compared with in controls. Furthermore, in comparison with healthy controls, no significant changes in the expression of TLR1 or TLR6-9 were observed. Additionally, TLR3 expression was downregulated in patients. Therefore, TLR3, TLR4 and TLR 5 were selected for subsequent investigation. It was then revealed that pomalidomide significantly promoted TLR3 expression, and inhibited the expression of TLR4 and TLR5 in PBMCs obtained from patients with AS. Therefore, it was hypothesized that TLR4 and TLR5 may promote the progression of AS, whereas TLR3 may suppress the progression of AS. Inhibitors of TLR4, including VGX-1027 and Eritoran, have been widely associated with several immune diseases (45-47). It was proposed that the inhibitors may also serve an important role in AS treatment; thus, an in-depth study involving the use of TLR4 inhibitors, such as the anti-retroviral protease inhibitor Saquinavir, in PBMCs and patients with AS that are resistant to standard treatment, is planned for the future.

As an anti-TNF- $\alpha$ drug, infliximab is widely used in clinical treatment of various inflammatory diseases, including AS (48-50). In the present study, the levels of inflammatory factors and TLRs were evaluated in patients with AS prior to and following infliximab treatment. It was observed that 
A

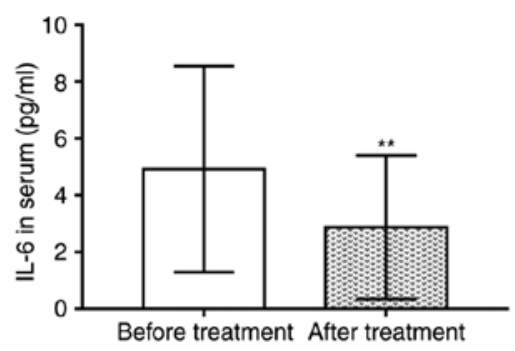

C

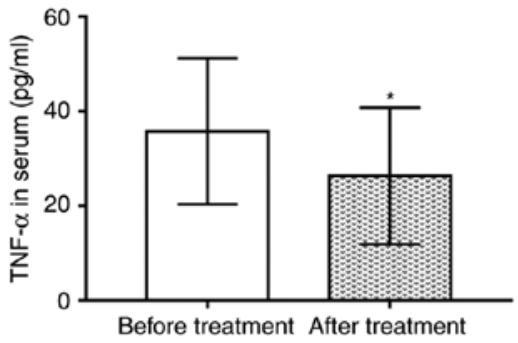

B

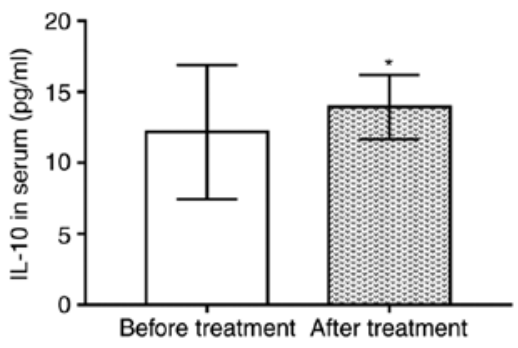

D

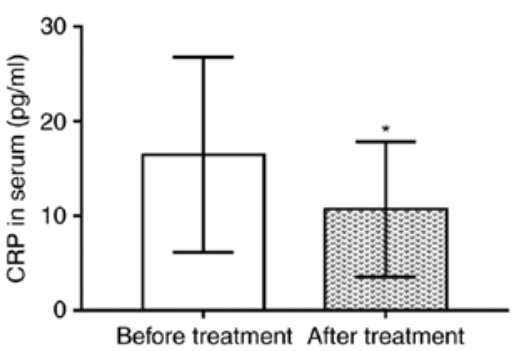

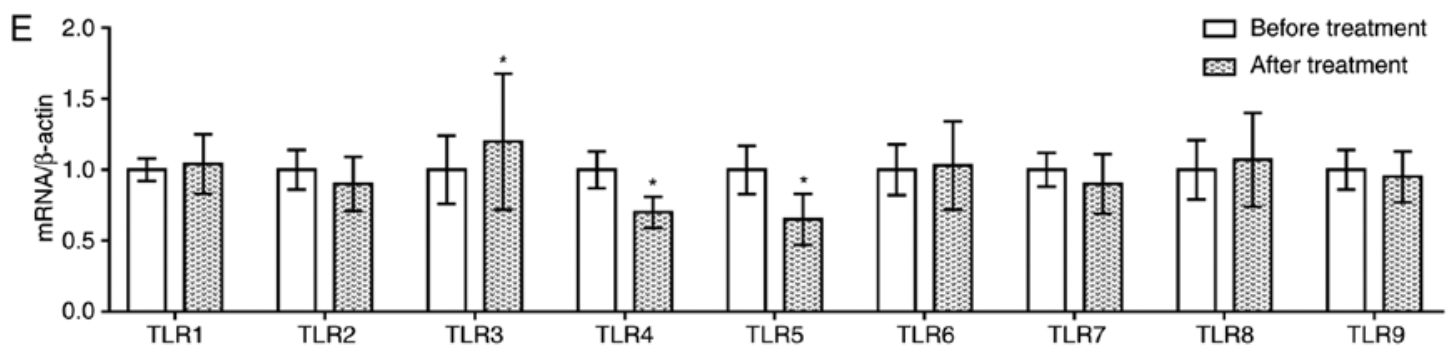

Figure 4. Upregulation of IL-10 and TLR3, and downregulation of IL-6, TNF- $\alpha$, CRP, TLR4 and TLR5 following the treatment of patients with AS using infliximab. Serum levels of (A) IL-6, (B) IL-10, (C) TNF- $\alpha$ and (D) CRP in patients with AS before and after treatment, as determined via ELISA. (E) mRNA levels of TLRs were detected via reverse transcription-quantitative PCR. ${ }^{*} \mathrm{P}<0.05,{ }^{* *} \mathrm{P}<0.01$ vs. before treatment. AS, ankylosing spondylitis; CRP, C-reactive protein; IL, interleukin; TLR, Toll-like receptor; TNF- $\alpha$, tumor necrosis factor- $\alpha$.

A

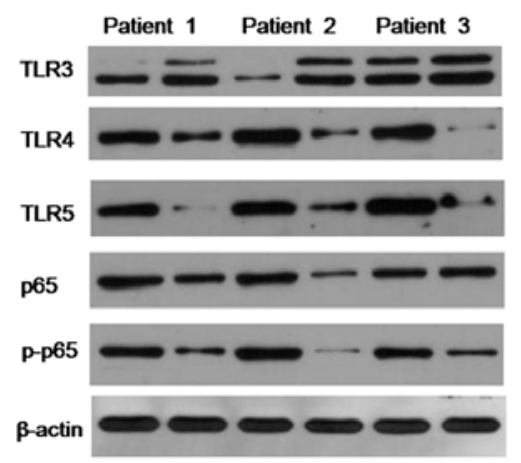

B

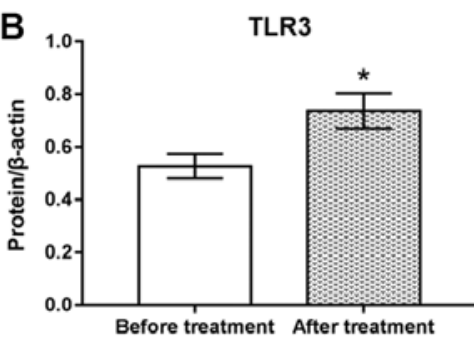

D

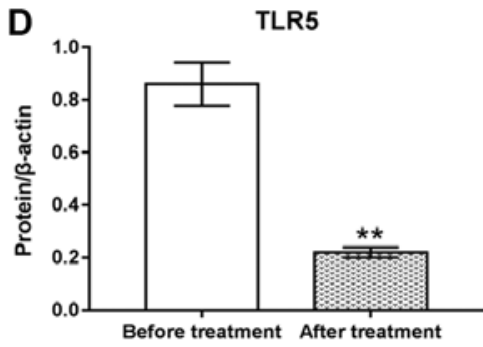

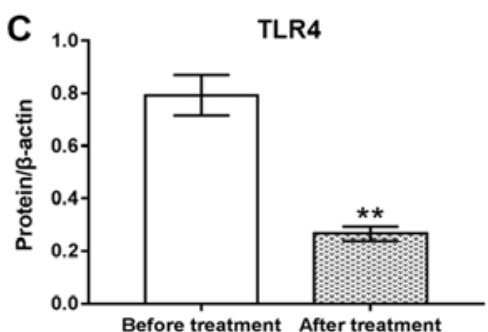

E

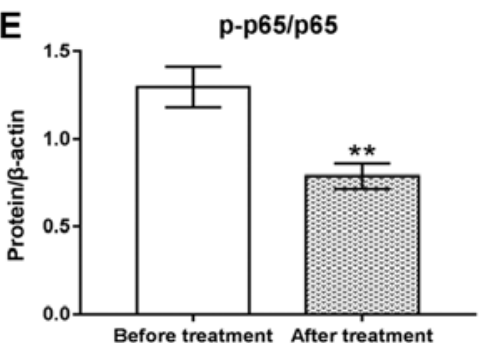

Figure 5. Upregulation of TLR3, and downregulation of TLR4, TLR5, p65 and p-p65 following the treatment of patients with AS using infliximab. (A) Western blotting was performed to determine the proteins levels of (B) TLR3, (C) TLR4, (D) TLR5 and (E) p-p65/p65 before and after patients with AS received treatment. ${ }^{*} \mathrm{P}<0.05,{ }^{* *} \mathrm{P}<0.01$ vs. before treatment. NF- $\kappa \mathrm{B}$, nuclear factor- $\kappa \mathrm{B} ; \mathrm{p}-$, phosphorylated; TLR, Toll-like receptor.

following infliximab treatment, the inflammatory response in patients was reduced, as determined by increased levels of IL-6, TNF- $\alpha$ and CRP, and enhanced levels of IL-10. Furthermore, TLR3 expression was upregulated, whereas the expression of TLR4 and TLR5 was downregulated following infliximab treatment. The findings were consistent with observations in PBMCs. It should be noted that infliximab exhibits certain side effects, including dyspnea, flushing, headache, rash, abdominal pain, diarrhea, back pain, chest pain and nausea (51-53). 
$\mathrm{NF}-\kappa \mathrm{B}$ is a key transcriptional regulator in the inflammatory response, and serves an important role in the development of AS $(18,54)$. TLRs are the potential catalyst for activation of the NF- $\kappa \mathrm{B}$ pathway, which has been reported to be involved in the occurrence of inflammation (55-57). Previous studies have demonstrated that $\beta$-D-mannuronic acid inhibited the activity of $\mathrm{AS}$ by blocking the TLR2/4/NF- $\kappa \mathrm{B}$ pathway $(55,56)$. Zhao et al (58) reported that astragaloside protected myocardial cells against cell apoptosis by suppressing the TLR4/NF- $\mathrm{B}$ pathway. Therefore, the expression of $\mathrm{NF}-\kappa \mathrm{B}$ pathway in patients with $\mathrm{AS}$, and PBMCs from these patients. It was revealed that TNF- $\alpha$ inhibitor decreased the p-p65/p65 ratio in PBMCs from patients. Additionally, infliximab reduced the phosphorylation of p65/p65 in patients with AS. The findings suggested that the $\mathrm{NF}-\kappa \mathrm{B}$ pathway was involved in the progression of AS; more specifically, the NF- $\kappa$ B pathway was suppressed when the progression of AS was blocked by infliximab.

In conclusion, the findings of the present study revealed that TNF- $\alpha$ inhibitor suppressed inflammatory responses in AS, increased TLR3 expression, and suppressed the expression of TLR4 and TLR5, and NF- $\kappa \mathrm{B}$ signaling. These observations indicated that TLRs and the NF- $\kappa \mathrm{B}$ pathway contributed to the regulation of the inflammatory response during AS. These findings provided novel insight for the potential inhibition of the development of AS. It was hypothesized that TLR4 and TLR5 may promote the progression of AS, and that TLR3 may suppress the progression of AS by suppressing $\mathrm{NF}-\kappa \mathrm{B}$ signaling; however, this hypothesis requires further validation.

\section{Acknowledgements}

Not applicable.

\section{Funding}

No funding was received.

\section{Availability of data and materials}

The datasets used and/or analyzed during the current study are available from the corresponding author on reasonable request.

\section{Authors' contributions}

JZ made substantial contributions to conception and design. RX, LW and JJ conducted data acquisition, and data analysis and interpretation. JZ drafted the article and critically revised it for important intellectual content. All authors gave final approval of the version to be published, and agree to be accountable for all aspects of the work in ensuring that questions related to the accuracy or integrity of the work are appropriately investigated and resolved.

\section{Ethics approval and consent to participate}

All patients provided written informed consent, and all experiments were approved by the Ethics Committee of Mingzhou Hospital of Zhejiang University.

\section{Patient consent for publication}

Not applicable.

\section{Competing interests}

The authors declare that they have no competing interests.

\section{References}

1. Chen D, He J, Lu C, Zhou J, Fang K, Liu X and Xu L: Increased expression of $\mathrm{T}$ cell immunoglobulin and mucin domain 4 is positively associated with the disease severity of patients with ankylosing spondylitis. Inflammation 38: 935-940, 2015.

2. Akkoc $\mathrm{N}$ and Khan MA: Overestimation of the prevalence of ankylosing spondylitis in the Berlin study: Comment on the article by Braun et al. Arthritis Rheum 52: 4048-4050, 2005.

3. Ng SC, Liao Z, Yu DT, Chan ES, Zhao L and Gu J: Epidemiology of spondyloarthritis in the People's Republic of China: Review of the literature and commentary. Semin Arthritis Rheum 37: 39-47, 2007.

4. Taurog JD, Chhabra A and Colbert RA: Ankylosing spondylitis and axial spondyloarthritis. N Engl J Med 374: 2563-2574, 2016.

5. Sari I, Öztürk MA and Akkoc N: Treatment of ankylosing spondylitis. Turk J Med Sci 45: 416-430, 2015.

6. Martins NA, Furtado GE, Campos MJ, Leitão JC, Filaire E and Ferreira JP: Exercise and ankylosing spondylitis with New York modified criteria: A systematic review of controlled trials with meta-analysis. Acta Reumatol Port 39: 298-308, 2014.

7. Mau W, Zeidler H, Mau R, Majewski A, Freyschmidt J, Stangel W and Deicher H: Clinical features and prognosis of patients with possible ankylosing spondylitis. Results of a 10-year followup. J Rheumatol 15: 1109-1114, 1988.

8. Husseinzadeh $\mathrm{N}$ and Davenport SM: Role of toll-like receptors in cervical, endometrial and ovarian cancers: A review. Gynecol Oncol 135: 359-363, 2014.

9. Lim KH and Staudt LM: Toll-like receptor signaling. Cold Spring Harb Perspect Biol 5: a011247, 2013.

10. Huggins T, Haught JC, Xie S, Tansky CS, Klukowska M, Miner MC and White DJ: Quantitation of endotoxin and lipoteichoic acid virulence using toll receptor reporter gene. Am J Dent 29: 321-327, 2016.

11. Shimizu M: Multifunctions of dietary polyphenols in the regulation of intestinal inflammation. J Food Drug Anal 25: 93-99, 2017.

12. Abhyankar MM, Orr MT, Lin S, Suraju MO, Simpson A, Blust M, Pham T, Guderian JA, Tomai MA, Elvecrog J, et al: Adjuvant composition and delivery route shape immune response quality and protective efficacy of a recombinant vaccine for entamoeba histolytica. NPJ Vaccines 3: 22, 2018.

13. Takakubo Y, Barreto G, Konttinen YT, Oki H and Takagi M: Role of innate immune sensors, TLRs, and NALP3 in rheumatoid arthritis and osteoarthritis. J Long Term Eff Med Implants 24: 243-251, 2014.

14. Zauner D, Quehenberger F, Hermann J, Dejaco C, Stradner MH, Stojakovic T, Angerer H, Rinner B and Graninger WB: Whole body hyperthermia treatment increases interleukin 10 and toll-like receptor 4 expression in patients with ankylosing spondylitis: A pilot study. Int J Hyperthermia 30: 393-401, 2014.

15. Gómez R, Castro A, Martínez J, Rodríguez-García V, Burgués O, Tarín JJ and Cano A: Receptor activator of nuclear factor Kappa B (RANK) and clinicopathological variables in endometrial cancer: A study at protein and gene level. Int J Mol Sci 19: pii: E1848, 2018

16. Yang JH, Lee E, Lee B, Cho WK, Ma JY and Park KI: Ethanolic extracts of Artemisia apiace $a$ hance improved atopic dermatitis-like skin lesions in vivo and suppressed TNF-alpha/IFN-gamma(-) induced proinflammatory chemokine production in vitro. Nutrients 10: pii: E806, 2018.

17. Taniguchi $\mathrm{K}$ and Karin $\mathrm{M}: \mathrm{NF}-\kappa \mathrm{B}$, inflammation, immunity and cancer: Coming of age. Nat Rev Immunol 18: 309-324, 2018.

18. Fang L, Liu J, Wan L, Zhu F, Tan B and Zhang P: Xinfeng capsule improves hypercoagulative state by inhibiting miR-155/NF- $\kappa \mathrm{B}$ signaling pathway in patients with active ankylosing spondylitis. Xi Bao Yu Fen Zi Mian Yi Xue Za Zhi 32: 1094-1098, 2016 (In Chinese). 
19. Noort AR, Tak PP and Tas SW: Non-canonical NF- $\kappa B$ signaling in rheumatoid arthritis: Dr Jekyll and Mr Hyde? Arthritis Res Ther 17: 15, 2015.

20. Shostak K and Chariot A: EGFR and NF- $\kappa B$ : Partners in cancer. Trends Mol Med 21: 385-393, 2015.

21. van der Linden S, Valkenburg HA and Cats A: Evaluation of diagnostic criteria for ankylosing spondylitis. A proposal for modification of the New York criteria. Arthritis Rheum 27: 361-368, 1984.

22. Misra RS, Bhattacharya S, Huyck HL, Wang JC, Slaunwhite CG, Slaunwhite SL, Wightman TR, Secor-Socha S, Misra SK, Bushnell TP, et al: Flow-based sorting of neonatal lymphocyte populations for transcriptomics analysis. J Immunol Methods 437: 13-20, 2016.

23. Muller GW, Chen R, Huang SY, Corral LG, Wong LM, Patterson RT, Chen Y, Kaplan G and Stirling DI: Aminosubstituted thalidomide analogs: Potent inhibitors of TNF-alpha production. Bioorg Med Chem Lett 9: 1625-1630, 1999.

24. Hoy SM: Pomalidomide: A review in relapsed and refractory multiple myeloma. Drugs 77: 1897-1908, 2017.

25. Huang YT, Cheng CC, Chiu TH and Lai PC: Therapeutic potential of thalidomide for gemcitabine-resistant bladder cancer. Int J Oncol 47: 1711-1124, 2015.

26. Livak KJ and Schmittgen TD: Analysis of relative gene expression data using real-time quantitative PCR and the 2(-Delta Delta C(T)) method. Methods 25: 402-408, 2001.

27. Rezaiemanesh A, Abdolmaleki M, Abdolmohammadi K, Aghaei H, Pakdel FD, Fatahi Y, Soleimanifar N, Zavvar M and Nicknam MH: Immune cells involved in the pathogenesis of ankylosing spondylitis. Biomed Pharmacother 100: 198-204, 2018.

28. Nicoletti F, Zaccone P, Di Marco R, Lunetta M, Magro G, Grasso S, Meroni P and Garotta G: Prevention of spontaneous autoimmune diabetes in diabetes-prone BB rats by prophylactic treatment with antirat interferon-gamma antibody. Endocrinology 138: 281-288, 1997.

29. Zaky DS and El-Nahrery EM: Role of interleukin-23 as a biomarker in rheumatoid arthritis patients and its correlation with disease activity. Int Immunopharmacol 31: 105-108, 2016.

30. El-Wakkad A, Hassan Nel M, Sibaii H and El-Zayat SR: Proinflammatory, anti-inflammatory cytokines and adiponkines in students with central obesity. Cytokine 61: 682-687, 2013.

31. Urushima H, Nishimura J, Mizushima T, Hayashi N, Maeda K and Ito T: Perilla frutescens extract ameliorates DSS-induced colitis by suppressing proinflammatory cytokines and inducing anti-inflammatory cytokines. Am J Physiol Gastrointest Liver Physiol 308: G32-G41, 2015.

32. Hou $\mathrm{C}, \mathrm{Wu} \mathrm{Q}$, Ouyang $\mathrm{C}$ and Huang T: Effects of an intravitreal injection of interleukin-35-expressing plasmid on pro-inflammatory and anti-inflammatory cytokines. Int J Mol Med 38: 713-720, 2016

33. Ji X, Zhou P, Zhong L, Xu A, Tsang ACO and Chan PKL: Smart surgical catheter for C-reactive protein sensing based on an imperceptible organic transistor. Adv Sci (Weinh) 5: 1701053, 2018.

34. Wu Y, Potempa LA, El Kebir D and Filep JG: C-reactive protein and inflammation: Conformational changes affect function. Biol Chem 396: 1181-1197, 2015.

35. Frasca D and Blomberg BB: Inflammaging decreases adaptive and innate immune responses in mice and humans. Biogerontology 17: 7-19, 2016.

36. Rusman T, Ten Wolde S, Euser SM, van der Ploeg T, van Hall O and van der Horst-Bruinsma IE: Gender differences in retention rate of tumor necrosis factor alpha inhibitor treatment in ankylosing spondylitis: A retrospective cohort study in daily practice Int J Rheum Dis 21: 836-842, 2018.

37. Shang J, Zhang Y, Jiang Y, Li Z, Duan Y, Wang L, Xiao J and Zhao Z: NOD2 promotes endothelial-to-mesenchymal transition of glomerular endothelial cells via MEK/ERK signaling pathway in diabetic nephropathy. Biochem Biophys Res Commun 484 435-441, 2017.

38. Lalancette-Hebert M, Faustino J, Thammisetty SS, Chip S, Vexler ZS and Kriz J: Live imaging of the innate immune response in neonates reveals differential TLR2 dependent activation patterns in sterile inflammation and infection. Brain Behav Immun 65: 312-327, 2017

39. Satoh T and Akira S: Toll-like receptor signaling and its inducible proteins. Microbiol Spectr: Dec 4, 2016 (Epub ahead of print). doi: 10.1128/microbiolspec.MCHD-0040-2016.

40. Sugitharini V, Pavani K, Prema A and Berla Thangam E: TLR-mediated inflammatory response to neonatal pathogens and co-infection in neonatal immune cells. Cytokine 69: 211-217, 2014.
41. Akira S, Takeda K and Kaisho T: Toll-like receptors: Critical proteins linking innate and acquired immunity. Nat Immunol 2: 675-680, 2001.

42. Kragstrup TW, Andersen T, Holm C, Schiøttz-Christensen B, Jurik AG, Hvid M and Deleuran B: Toll-like receptor 2 and 4 induced interleukin-19 dampens immune reactions and associates inversely with spondyloarthritis disease activity. Clin Exp Immunol 180: 233-242, 2015.

43. Assassi S, Reveille JD, Arnett FC, Weisman MH, Ward MM, Agarwal SK, Gourh P, Bhula J, Sharif R, Sampat K, et al: Whole-blood gene expression profiling in ankylosing spondylitis shows upregulation of Toll-like receptor 4 and 5. J Rheumatol 38: 87-98, 2011 .

44. De Rycke L, Vandooren B, Kruithof E, De Keyser F, Veys EM and Baeten D: Tumor necrosis factor alpha blockade treatment down-modulates the increased systemic and local expression of toll-like receptor 2 and Toll-like receptor 4 in spondylarthropathy. Arthritis Rheum 52: 2146-2158, 2005.

45. Fagone P, Muthumani K, Mangano K, Magro G, Meroni PL, Kim JJ, Sardesai NY, Weiner DB and Nicoletti F: VGX-1027 modulates genes involved in lipopolysaccharide-induced Toll-like receptor 4 activation and in a murine model of systemic lupus erythematosus. Immunology 142: 594-602, 2014.

46. Stojanovic I, Cuzzocrea S, Mangano K, Mazzon E, Miljkovic D, Wang M, Donia M, Al Abed Y, Kim J, Nicoletti F, et al: In vitro, ex vivo and in vivo immunopharmacological activities of the isoxazoline compound VGX-1027: Modulation of cytokine synthesis and prevention of both organ-specific and systemic autoimmune diseases in murine models. Clin Immunol 123: 11-323, 2007.

47. Younan P, Ramanathan P, Graber J, Gusovsky F and Bukreyev A: The Toll-like receptor 4 antagonist eritoran protects mice from lethal filovirus challenge. MBio 8: pii: e00226-17, 2017.

48. Codreanu C, Śírová K, Jarosova K and Batalov A: Assessment of effectiveness and safety of biosimilar infliximab (CT-P13) in a real-life setting for treatment of patients with active rheumatoid arthritis or ankylosing spondylitis. Curr Med Res Opin 34: 1763-1769, 2018.

49. Osswald D, Rameau AC, Speeg-Schatz C, Terzic J and Sauer A: Clinical and epidemiological profile of pediatric uveitis, course of inflammatory uveitis treated with anti-TNF alpha. J Fr Ophtalmol 41: 447-452, 2018 (In French).

50. Siljehult F, Ärlestig L, Eriksson C and Rantapää-Dahlqvist S: Concentrations of infliximab and anti-drug antibodies in relation to clinical response in patients with rheumatoid arthritis. Scand J Rheumatol 47: 345-350, 2018.

51. Wasserman MJ, Weber DA, Guthrie JA, Bykerk VP, Lee P and Keystone EC: Infusion-related reactions to infliximab in patients with rheumatoid arthritis in a clinical practice setting: Relationship to dose, antihistamine pretreatment, and infusion number. J Rheumatol 31: 1912-1917, 2004.

52. Kim BY and Kim HS: Phlegmonous gastritis in an ankylosing spondylitis patient treated with infliximab. Korean J Intern Med 32: 945-946, 2017.

53. Maksymowych WP: Ankylosing spondylitis. Not just another pain in the back. Can Fam Physician 50: 257-262, 2004.

54. Dong M, Yu D, Duraipandiyan V and Abdullah Al-Dhabi N: The protective effect of chrysanthemum indicum extract against ankylosing spondylitis in mouse models. Biomed Res Int 2017: $8206281,2017$.

55. Aletaha S, Haddad L, Roozbehkia M, Bigdeli R, Asgary V, Mahmoudi M and Mirshafiey A: M2000 ( $\beta$-D-Mannuronic Acid) as a novel antagonist for blocking the TLR2 and TLR4 downstream signalling pathway. Scand J Immunol 85: 122-129, 2017.

56. Roozbehkia M, Mahmoudi M, Aletaha S, Rezaei N, Fattahi MJ, Jafarnezhad-Ansariha F, Barati A and Mirshafiey A: The potent suppressive effect of $\beta$-d-mannuronic acid (M2000) on molecular expression of the TLR/NF-kB signaling pathway in ankylosing spondylitis patients. Int Immunopharmacol 52: 191-196, 2017.

57. Wu GJ, Lin YW, Chuang CY, Tsai HC and Chen RM: Liver nitrosation and inflammation in septic rats were suppressed by propofol via downregulating TLR4/NF- $\mathrm{B}$-mediated iNOS and IL-6 gene expressions. Life Sci 195: 25-32, 2018.

58. Zhao Y, Liu Z and Zhang H: Astragaloside protects myocardial cells from apoptosis through suppression of the TLR4/NF-kB signaling pathway. Exp Ther Med 15: 1505-1509, 2018.

This work is licensed under a Creative Commons Attribution-NonCommercial-NoDerivatives 4.0 International (CC BY-NC-ND 4.0) License. 